\title{
Writing therapy
}

“I keep notebooks which are the footprints of my thoughts, tracks of journeys, curiosity-paths and desire-lines."

\author{
Jay Griffiths, Author
}

In the distant past I started to suggest to patients that they might like to write down their stories as a form of therapy. ${ }^{1}$ They could write me a letter or write a letter to some significant person in their lives that would help them coordinate their thoughts and emotions.

Even nowadays patients may feel inhibited in the often intense atmosphere of the medical consultation, so the idea of writing down one's anxieties and emotional conflicts may help the patients put their illness narratives in some form of order. It may also help clarify their thoughts in an unrushed way in the safety of their homes. Now, in this computer age, I suggest that they can make files and incrementally add to the file as further thoughts or situations arise. In this way, the author Jay Griffiths records that when she was in a period of manic depression that "I began trying to write down what I felt in the moments that I was collected enough. The written words anchored me and gave me a sense of safety as if a line of words across the page were a life line."

I suggest a few titles for the files such as Black Holes, Sunshine Days or even The Wobble List to describe the feelings and triggers that cause a wobble and also a list of things to do during a wobble.

It was a patient who first suggested this substitute for an oral history in the consulting room when the patient may not want to worry the doctor with a long story. She was a journalist and a playwright so perhaps she felt easier in the medium that she normally worked in. I looked after her for a period that occupied most of her 30s. She fought every day of those years as metastatic cancer of the breast inexorably ulcerated her skin, fractured her bones and broke her back but never her spirit. She was eloquent, self-opinionated and at times impossible, but then so am I. She would never believe anything I said until I had talked myself blue in the face. Everything was argued from the obverse. Just before she died she ended a letter "I'm glad I drive you to distraction, that's my prerogative as you can't heal me. Go and get some inspiration for I need you for my expiration." In her letters she exorcized her fear and impotent rage against the gods of the universe. In her consultations she exposed my superficial humanity with her courage.

Writing therapy has now been more formalised as "expressive writing" or "written disclosure therapy" and research is beginning to show that it may help for a variety of conditions from anxiety and depression to improvement in blood pressure and asthma. ${ }^{2}$ Nevertheless, writing is not a universal panacea. For many people it may not be an easy or suitable method of expression whereas for others it may help release the burden of the untold story.

A young woman with severe fibromyalgia recently emailed me (I assume the future will be e-Mail Therapy or Web-Based Therapy) a poem. Part of the poem goes:

I breathe again and again

It feels that is all I am doing day after day.

In and Out.

Rising in the morning only to sit and fight for the will to breathe,

waiting for the night to come.

I convince myself that I am content with the loneliness.

She has normal lungs but has difficulty breathing when she is anxious and is partly using the word or verb "breath" in this context as a metaphor for "spirit" similar to Umoya in isiZulu and Pneuma in Greek.

In this way writing may provide an uncritical channel to "get things off one's chest" as a therapeutic exercise. Rather than keeping a diary or journaling, writing therapy can also have a more structured format of recording or describing a traumatic event or emotion over a certain period of time.

Patients are reassured that there are no forbidden subjects and they can include expletives. "You cannot write the wrong thing." The spelling and grammar is not important and after a period of time the piece can be revisited, added to or reworked.

For my own therapy, I have built up a long letter, over the years, to the managers of the Departments of Health telling them a few home truths. It is one of my largest files with plenty of bad language and expletives.

\section{References}

1. Ellis C. Epistotherpay. Br Med J. 1989;299:1250.

2. Mugerwa S, Holden JD. Writing Therapy: A New Tool for General Practice? Br J Gen Practice. 2012;620:661-3.

Chris Ellis is a family physician in Pietermaritzburg, KwaZulu-Natal

50 of his previous columns have now been put into book form called:

Peripheralia. Digressions from Medical Practice.

It is available online at www.amazon.com ebooks.

E mail: cristobalellis@gmail.com 